\title{
AN ADAPTIVE HARMONIC COMPENSATION STRATEGY FOR THREE-PHASE SHUNT ACTIVE POWER FILTER BASED ON DOUBLE SECOND-ORDER GENERALIZED INTEGRATOR WITH PREFILTER
}

\begin{abstract}
This study presents a straightforward adaptive prefiltering algorithm based on a double second-order generalized integrator with prefilter to solve one of the power quality issues, this algorithm is in charge of the determination of the reference harmonic currents in the control of three-phase shunt active power filter which presents an effective way to enhance the grid current quality. The proposed algorithm is used twice, to extract the harmonic currents produced by the non-linear loads and be an interesting part in the estimation of the frequency and amplitude of the fundamental voltage in various anomalies which can be noticed on the grid voltage. The performance, precision, and robustness of the proposed method are evidenced under balanced, unbalanced, and distorted grid voltage in the simulation and experimental results obtained by the implementation of the shunt active power filter on MATLAB-Simulink environment and the dSPACE 1104 platform respectively. References 17, tables 2, figures 11 .
\end{abstract}

Key words: SOGI-WPF, SAPF, harmonic currents, power quality, DSOGI-PLL-WPF.

Аннотация. В данной работе представлен простой адаптивный алгоритм предфильтрации, основанный на двойном обобценном интеграторе с предфильтром второго порядка (DSOGI-WPF) для решения одного из вопросов качества электроэнергии. Данный алгоритм отвечает за определение опорных гармонических токов при контроле трехфазного фильтра шунта активной мощности (SAPF). Предложенный алгоритм используется дважды: для извлечения гармонических токов, создаваемых нелинейными нагрузками, и также является интересной частью оценки частоты и амплитуды основного напряжения при различных аномалиях, которые можно заметить по напряжению сети. Эффективность, точность и надежность предложенного метода подтверждаются при сбалансированном, несбалансированном и искаженном напряжении сети результатами моделирования и экспериментов, полученными при реализации SAPF в среде MATLAB-Simulink и платформе dSPACE 1104, соответственно. Библ. 17, табл. 2, рис. 11.

Ключевые слова: обобщенный интегратор с предфильтром второго порядка (SOGI-WPF), фильтр шунта активной мощности (SAPF), гармонические токи, качество электроэнергии, двойной обобщенный интегратор с предфильтром второго порядка с фазовой синхронизацией (DSOGI-PLL-WPF).

Introduction. The situation at the level of electrical energy networks has become very worrying, the quality of the current in electrical installations is undeniably deteriorating and some disturbances can act on the proper operation of many equipment and loads connected to the grid [1]. Therefore, it becomes a major concern for the distributors of this energy and its customers, this degradation results directly from the proliferation of charges that consume a non-sinusoidal current, called «non-linear loads», whereas using this kind of loads is not inevitable in the conversion and control of electrical power in different domains of industrial or domestic installations $[2,3]$.

In order to clean up the grid from the harmonic pollution there are several methods have been used, such as passive filter, where it can prevent harmonic currents from spreading in the grid, but, this type of filter has certain problems, like shortcoming of adaptability during variations of the impedance of grid and the load, considerable size, etc. [4]. To overcome the drawbacks of passive filter, the SAPF (shunt active power filter) presents a good alternative solution, which provides an unprecedented capacity for compensation and correction the harmonic distortions generated by non-linear loads. The role of SAPF based on the continuous injection of current at the connection point or PCC (point of common coupling), this current corresponds at any time to the harmonic current components absorbed by the load. In this way, the current supplied by the energy source remains sinusoidal [5].
To perform the SAPF task under any constraint that may appear in the grid (imbalance, frequency variation and so on), several methods of control and extraction of harmonic currents have been implemented in the time domain. Some have used in the balanced grid such as synchronous reference frame theory [6, 7], PQ theory [8], [9], others based on artificial neural networks have proposed in [10-12], which have proved its accuracy and performance in estimation of harmonic currents, but those structures present large complexity. In [13], the method based on multi second-order generalized integrator (MSOGI) has benne used to extract the multiple harmonic currents, but this structure cannot identify the inspected harmonics as the sub-harmonics or harmonics that have frequencies below the fundamental, furthermore, its implementation leads to increasing computing time [14]. A third-order complex-vector prefilter [15] known as third-order sinusoidal integrator has used in [17].

For the purpose of enhancing the performance of SAPF at high grid distortion, this paper employs an adaptive prefiltering method based on two-order SOGI to extract the harmonic currents and estimate the grid frequency, the two-order SOGI known as the secondorder generalized integrator with prefilter SOGI-WPF in [14]. For the first time, the SOGI-WPF has been used in double SOGI-WPF structure or DSOGI-WPF with the frequency lock loop in the photovoltaic system to estimate the frequency and improve the speed of voltage sequence detection under abnormal grid conditions and cancel out

(c) S. Kalkoul, H. Benalla, K. Nabti, R. Abdellatif 
the DC offset from the input signal [14]. In [16], the DSOGI-WPF is named as dual SO-SOGI, which has adopted as a step before phase detector PD in PLL (phaselocked loop) to generate the fundamental source current in distribution static synchronous compensator.

The goal of this paper is applying the double second-order generalized integrator with prefilter structure to extract the reference harmonic currents in the control of three-phase shunt active power filter and improve its operation under unusual grid voltage conditions (unbalanced, distorted). The method of double second-order generalized integrator with prefilter will be used to estimate the grid frequency, positive sequence components of the grid voltage, and extract the harmonic current components in the grid.

Description of the studied network. The general structure of SAPF is shown in Fig. 1, in addition to the grid elements (voltage source, grid impedance, and nonlinear load). The SAPF constitutes of two parts. The first one is the power circuit which consists of a three-phase two-level voltage inverter fed by a DC-link capacitor $\left(C_{d c}\right)$, the inverter is connected to the PCC through an inductance $L_{f}$ and a resistance $R_{f}$ which represent the output filter. The second part represents the control circuit, its first phase uses the method based on DSOGIWPF to extract the reference harmonic currents and estimate the instantaneous angular frequency of the fundamental voltage $\left(\omega_{1}\right)$, a corrector of the $V_{d c}$ voltage at terminals of capacitor $C_{d c}$ is used to ensures a sufficient and non-fluctuations supply to the inverter by keeping the measured $V_{d c}$ voltage at the reference voltage (in this case, PI corrector has been implemented), finally, a modulator based on the PWM technique for generating the pulses of the IGBTs of the inverter.

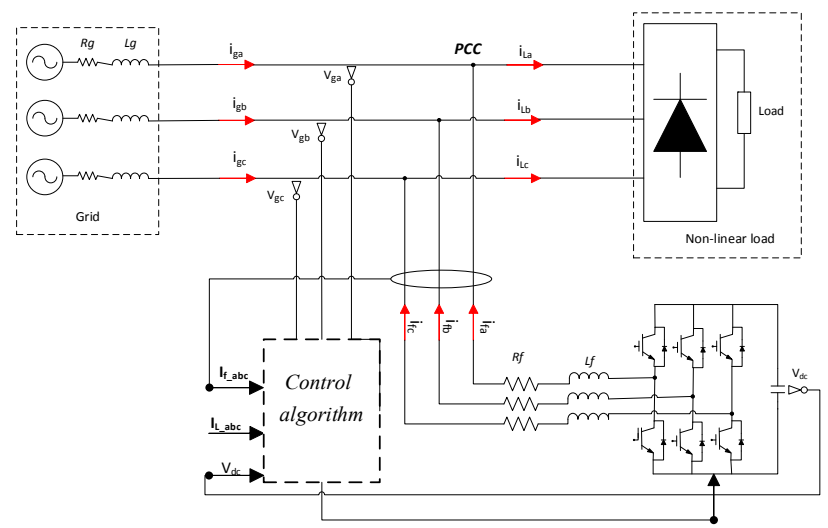

Fig. 1. Scheme diagram of three-phases SAPF

Second-order generalized integrator with prefilter. Fig. 2 shows the structure of the second-order generalized integrator with prefilter. Which is constituted of two SOGI connected in series, this allows building a fourth-order band-pass filter system for the in-phase and a fourth-order low-pass filter system for quadrature-phase. The $k_{1}$ and $k_{2}$ represent the proper gains of each SOGI, where $k_{1}=2 \zeta 1$ and $k_{2}=2 \zeta 2$ ( $\zeta 1$ and $\zeta 2$ are the damping factors). For high-performance of the SOGI-WPF, those damping factors should be equals i.e. $\zeta 1=\zeta 2=\zeta$ [14] The relation between the input signal and outputs in
SOGI-WPF can be summarized from the block diagram presented in Fig. 2 by the transfer functions defined as

$$
\begin{gathered}
H(s)=\frac{V_{1}(s)}{V_{g}(s)}=\left(\frac{2 \zeta \omega_{n} s}{s^{2}+2 \zeta \omega_{n} s+\omega_{n}^{2}}\right)^{2} ; \\
q H(s)=\left(\frac{2 \zeta \omega_{n} s}{s^{2}+2 \zeta \omega_{n} s+\omega_{n}^{2}}\right)\left(\frac{2 \zeta \omega_{n}^{2}}{s^{2}+2 \zeta \omega_{n} s+\omega_{n}^{2}}\right) .
\end{gathered}
$$

The transfer functions of SOGI are

$$
\begin{gathered}
G(s)=\frac{V_{1}^{\prime}(s)}{V_{g}(s)}=\frac{2 \zeta \omega_{n} s}{s^{2}+2 \zeta \omega_{n} s+\omega_{n}^{2}} ; \\
q G(s)=\frac{q V_{1}^{\prime}(s)}{V_{g}(s)}=\frac{2 \zeta \omega_{n}^{2}}{s^{2}+2 \zeta \omega_{n} s+\omega_{n}^{2}} .
\end{gathered}
$$

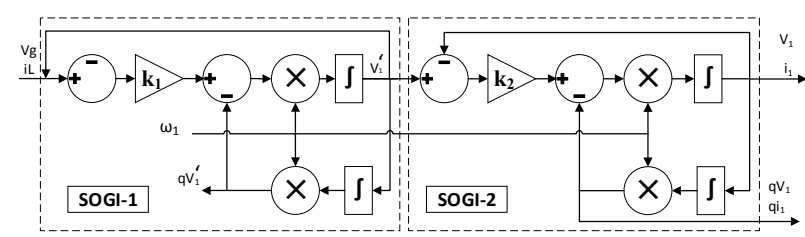

Fig. 2. Block diagram of SOGI-WPF

The bode plots of the SOGI and SOGI-WPF transfer functions are shown in Fig. 3. From the bode plots, it can be seen that the SOGI-WPF allows overcoming the drawbacks of the basic SOGI by eliminating the DC-offset from the quadrature signal and has a high performance at sub-harmonics attenuation of the input signal, which makes the SOGI-WPF more efficient and accurate at the separation of the fundamental component and the harmonic components.

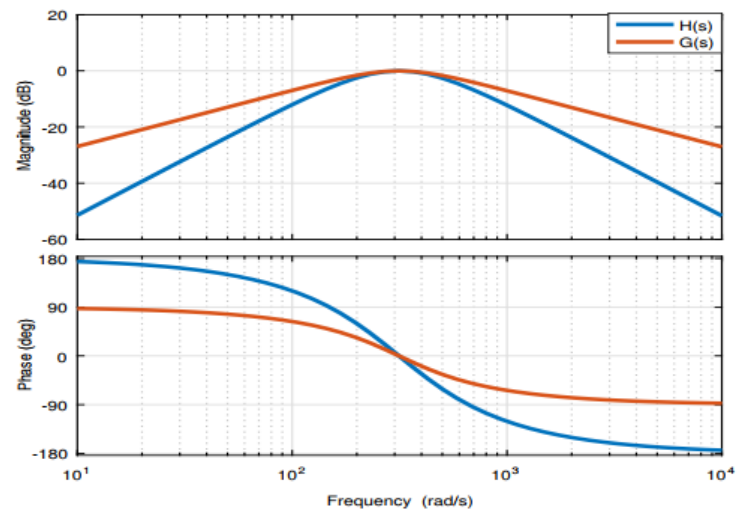

$a$

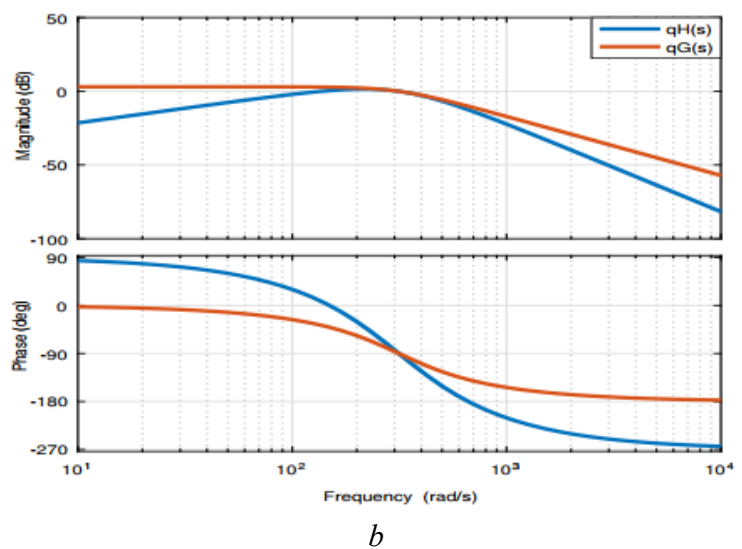

Fig. 3. Bode plot of SOGI and SOGI-WPF: $a-H(s)$ and $G(s)$ of in-phase voltage, $b-q H(s)$ and $q G(s)$ of quadrature voltage 
Modeling the control of shunt active power filter. The proposed control algorithm that is depicted in Fig. 4, aims to generate the pulses of the inverter using the reference harmonic currents for compensating the grid harmonics produced by the nonlinear load.

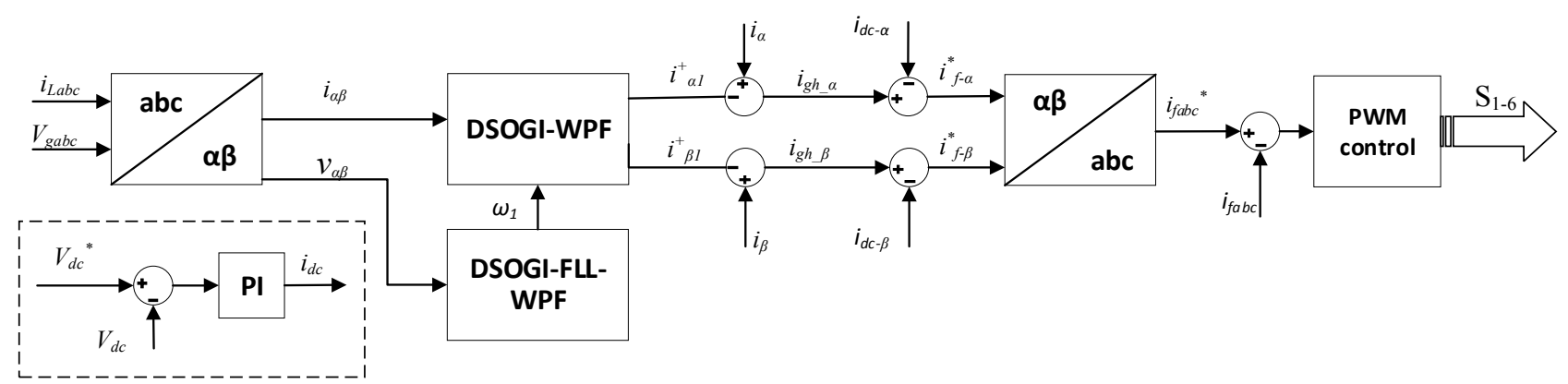

Fig. 4. Structure of the proposed control

1. Double second-order generalized integrator with prefilter. In this sub-section, the proposed method based on DSOGI-WPF, which is illustrated in Fig. 5, is employed as a filter to extract the harmonic components of the input signal and detect its positive sequence components.

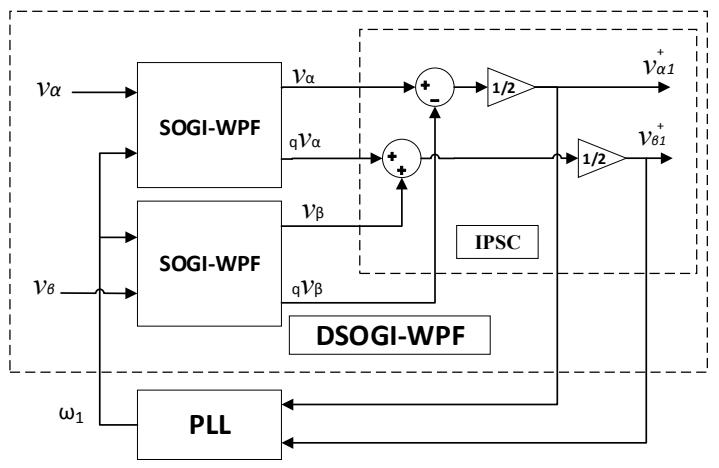

$a$

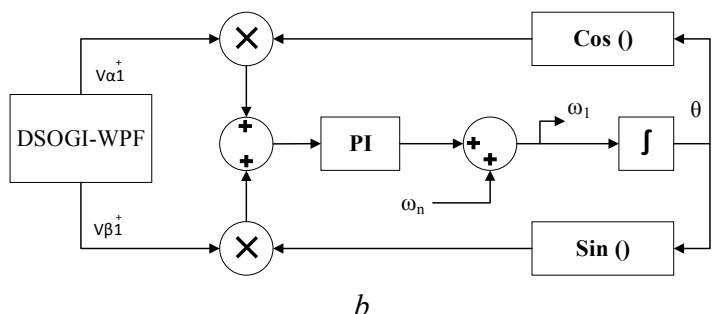

Fig. 5. Block diagram of the proposed synchronization method: $a$-DSOGI-WPF, $b$-DSOGI-PLL-WPF

As mentioned above, the DSOGI-WPF has two identical variables in each SOGI-WPF, where $k_{1}=k_{2}=2 \zeta$. To have an effective filtering performance with a fast dynamic response, the $k_{1}$ and $k_{2}$ are set to 0.8 . The two SOGI-WPF lead to output the signals in-phase and quadrature-phase for $\alpha$ and $\beta$ components $\left(v_{\alpha}, v_{\beta}, q v_{\alpha}\right.$, and $\left.q v_{\beta}\right)$. To compute the positive sequence components $\left(v_{\alpha 1}^{+}, v_{\beta 1}^{+}\right)$these signals are used as the inputs of instantaneous positive-sequence components IPSC calculation block as shown in Fig. 5, the IPSC in the stationary $\alpha \beta$ reference frame is given as

$$
v_{\alpha \beta 1}^{+}=\frac{1}{2}\left[\begin{array}{cc}
1 & -q \\
q & 1
\end{array}\right] v_{\alpha \beta 1},
$$

where $q=e^{-j(\pi / 2)}$, which represents a 90-lagging phaseshift operator. The amplitude of the positive sequence components detected by the DSOGI-WPF can be expressed as

$$
\left|V_{1}^{+}\right|=\sqrt{\left(v_{\alpha 1}^{+}\right)^{2}+\left(v_{\beta 1}^{+}\right)^{2}} .
$$

To obtain the positive sequence components of current, the same procedure as precedent is applied by using the DSOGI-WPF and IPSC blocks.

2. Frequency estimation and grid harmonics extraction. In order to estimate the frequency of the PCC voltage, the fundamental positive sequences $\left(v_{\alpha 1}^{+}, v_{\beta 1}^{+}\right)$ obtained by IPSC are straightforwardly used to implement the PLL based on in-quadrature signal generation as shown in Fig. 5, which is known as the DSOGI-PLLWPF. The PLL that is illustrated in Fig. 5 uses the DSOGI-WPF as a prefiltering stage in the stationary reference frame $(\alpha \beta)$ to eliminate the negative impact of the distorting harmonics, which makes it more accurate at the estimation of the frequency and the amplitude of the positive sequence. The frequency/phase generated by the PLL allows providing the phase-angle for the trigonometric functions and the fundamental frequency to the DSOGI-WPF. The PI controller gains of the SOGIPLL-WPF are set to $k_{p}=0.3$ and $k_{i}=0.5$.

Identifying the positive-sequence for the grid current and make the SOGI-WPF adaptable with any variation may have occurred on the frequency by using SOGI-PLLWPF allows extracting the harmonic current produced because of non-linear load by simple subtraction as illustrated in Fig. 4. In this case, the grid-harmonic currents in $\alpha \beta$ reference frame can be calculated as

$$
\begin{aligned}
& i_{g h-\alpha}=i_{\alpha}-i_{\alpha 1}^{+} . \\
& i_{g h-\beta}=i_{\beta}-i_{\beta 1}^{+} .
\end{aligned}
$$

3. $V_{d c}$ regulator. To maintain the DC-link in SAPF at optimal reference voltage and lower the fluctuations on it, a PI controller is applied in a closed-loop as shown in Fig. 6. From this figure, the transfer function of the closed-loop system is depicted as

$$
\frac{V_{d c}}{V_{d c}^{*}}=\frac{k_{p} s+k_{i}}{C_{d c} s^{2}+k_{p} s+k_{i}} .
$$

The equation (9) refers to the second-order transfer function. Thus, $k_{p}=2 \zeta C_{d c} \omega_{n}$ and $k_{i}=C_{d c} \omega_{n}^{2}$, where 
$\omega_{n}$ is the natural frequency, $\zeta$ is the damping factor and is taken as 0.707 .

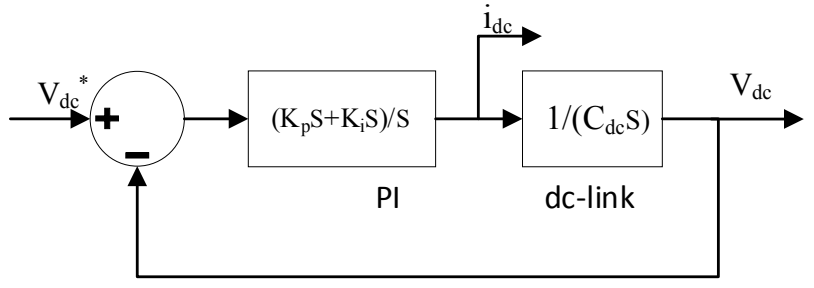

Fig. 6. Scheme of $V_{d c}$ control

4. Reference currents computation. The reference currents for SAPF gather the harmonic currents of the grid that must be compensated and the currents necessary for the $V_{d c}$ to be stable at the desired reference, which can be calculated as

$$
i_{f}^{*}=i_{g h}-i_{d c} .
$$

The $i_{f}^{*}$ in stationary $\alpha \beta$ frame can be written as

$$
\begin{aligned}
& i_{f-\alpha}^{*}=i_{g h-\alpha}-i_{d c-\alpha} ; \\
& i_{f-\beta}^{*}=i_{g h-\beta}-i_{d c-\beta},
\end{aligned}
$$

where the $i_{d c}$ in stationary $(\alpha \beta)$ reference frame is calculated as

$$
\begin{gathered}
i_{d c-\alpha}=i_{d c} \frac{v_{\alpha 1}^{+}}{\left|V_{1}^{+}\right|} . \\
i_{d c-\beta}=i_{d c} \frac{v_{\beta 1}^{+}}{\left|V_{1}^{+}\right|} .
\end{gathered}
$$

The $i_{f-\alpha}^{*}$ and $i_{f-\beta}^{*}$ are transformed to $i_{a b c}^{*}$ by inverse Clarke's transformation. Finally, the PWM control generates the pulses of the inverter using error

between the reference currents $i_{a}^{*}, i_{b}^{*}, i_{c}^{*}$ and the injected currents $i_{f a}^{*}, i_{f b}^{*}, i_{f c}^{*}$ respectively.

Simulation and experimental results performance. The simulation results have been obtained by modeling the SAPF on MATLAB-Simulink environment according to the topology presented in Fig. 1 and the different parameters of the system are illustrated in Table 1. The proposed algorithm is evaluated under balanced, distorted, and unbalanced voltage. To prove the performance of the SAPF in real-time, the control algorithm which based on DSOGI-WPF and DSOGIPLL-WPF (Fig. 4 and Fig. 5 respectively) in extracting the reference harmonic currents has been executed by using the digital signal processor (dSPACE 1104 platform). As shown in Fig. 7, the measured load currents, injected harmonic currents by the SAPF, voltages of the PCC, and voltage of the DC-bus are connected via the Analog to Digital Conversion inputs of the dSPACE. The drivers of the IGBT modules of the inverter are controlled by the pulses sent via Digital output.

Table 1

System parameters

\begin{tabular}{|c|c|}
\hline Parameters & Values \\
\hline Grid voltage & $V_{g_{-} \max }=100 \mathrm{~V}, f=50 \mathrm{~Hz}$ \\
\hline Source impedance & $R_{g}=0.5 \Omega, L_{g}=1 \mathrm{mH}$ \\
\hline DC-link & $C_{d c}=1100 \mu \mathrm{F}, V_{d c}=280 \mathrm{~V}$ \\
\hline Output filter & $R_{f}=0.6 \Omega, L_{f}=12.5 \mathrm{mH}$ \\
\hline Non-linear load & Three-phase rectifier, $R_{L}=33 \Omega$ \\
\hline PLL-PI gains & $K_{p}=0.3, K_{i}=0.5$ \\
\hline SOGI-WPF gains & $k_{1}=k_{2}=0.8$ \\
\hline DC-link control gains & $K_{p}=0.49, K_{i}=109$ \\
\hline Switching frequency & $7 \mathrm{kHz}$ \\
\hline Sampling frequency & $14 \mathrm{kHz}$ \\
\hline
\end{tabular}

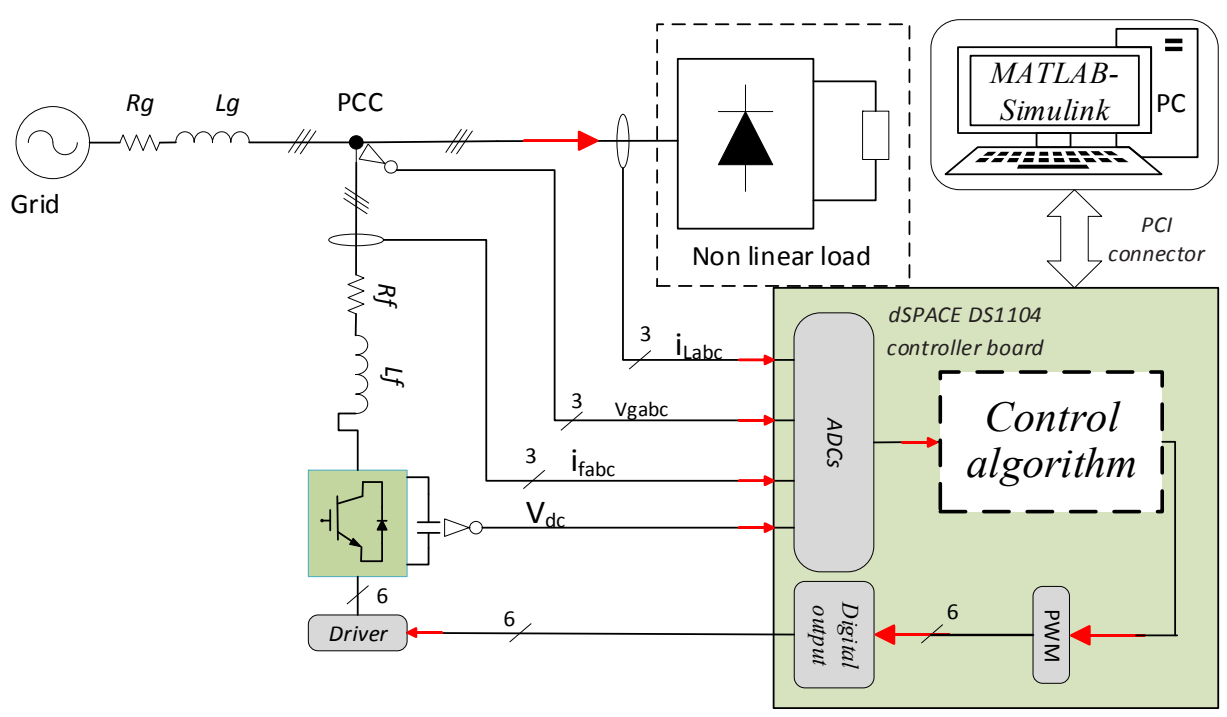

Fig. 7. Experimental schematic of SAPF

1. Behavior of the SAPF under sinusoidal grid voltage condition. Fig. 8, $a$ and Fig. 8,b respectively show the simulation and the experimental results of the SAPF under sinusoidal supply voltage. Indeed, the voltage at the PCC is slightly affected by the harmonics caused by the main network whose voltages $V_{g a}, V_{g b}, V_{g c}$ have a total harmonic distortion (THD) of $1,1.2$, and $1.4 \%$ respectively. The performance of the control based on DSOGI-WPF is remarkable where the harmonized currents generated by the load are almost compensated by the SAPF currents which give back the waveform of the source current sinusoidal. Table 2 illustrates the THD of 
the load and the source currents, which shows that the THD of the source currents is greatly reduced.

Table 2

Current total harmonic distortion

\begin{tabular}{|l|c|c|c|c|c|c|}
\hline \multirow{2}{*}{} & \multicolumn{3}{|c|}{$\begin{array}{c}\text { THD (\%) load } \\
\text { currents }\end{array}$} & \multicolumn{3}{c|}{$\begin{array}{c}\text { THD (\%) source } \\
\text { currents }\end{array}$} \\
\cline { 2 - 7 } & $i_{\mathrm{La}}$ & $i_{\mathrm{Lb}}$ & $i_{\mathrm{Lc}}$ & $i_{g a}$ & $i_{g b}$ & $i_{g c}$ \\
\hline Balanced grid voltage & 21.8 & 22.3 & 23.1 & 3.5 & 3.6 & 4.2 \\
\hline Distorted grid voltage & 19.1 & 19.3 & 20 & 4.5 & 4.3 & 4.6 \\
\hline $\begin{array}{l}\text { Unbalanced grid } \\
\text { voltage }\end{array}$ & 19.1 & 21.9 & 23.1 & 3.9 & 4 & 4.3 \\
\hline
\end{tabular}

2. Behavior of the SAPF under distorted grid voltage condition. In this study, the waveform of the grid voltage has a deformed shape due to the presence of harmonics, the voltage of each phase is perturbed by a high amount of the -5 th and +7 th harmonic components with a THD of $13,14.7$, and $13.2 \%$ for $V_{g a}, V_{g b}, V_{g c}$ respectively.

Figure 9 illustrates the performance of the proposed SAPF command while the supply voltage is distorted. As observed in Fig. 9, $a$ and Fig. 9,b, the source current has a shape close to sinusoidal in the simulation and experimental results, which confirms the robustness and the precision of the DSOGI-WPF. The acceptable THD of the source current which describes in Table 2 also demonstrates that the proposed algorithm based on DSOGI-PLL-WPF makes the SAPF well synchronized with the fundamental frequency of the PCC voltage which is affected by harmonics.

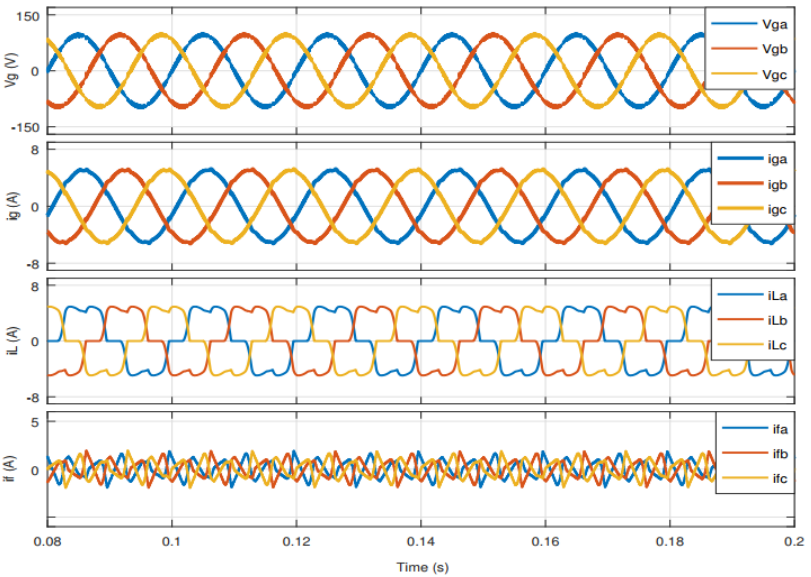

$a$
3. Behavior of the SAPF under unbalanced grid voltage condition. In this situation, the grid voltage is characterized by the following measurements: the amplitudes of the three phases are $V_{g a}=110 \mathrm{~V}, V_{g b}=96 \mathrm{~V}$, $V_{g c}=82 \mathrm{~V}$ with a total harmonic distortion of $1.8,3.7$, and $7.7 \%$ respectively. The voltage unbalancing is achieved by inserting resistors of different values in series with the three phases. In Fig. 10, $a$ and Fig. 10,b, the simulation and the experimental results are presented, where the performance of the SAPF under distorted-unbalanced voltage is validated. It is clear that the efficiency of SAPF is not influenced by distorted-unbalanced voltage. The THD of each phase of the source and load currents is illustrated in Table 2, where the recommendations of the IEEE standard concerning the THD are observed.

4. Comparison between SOGI-PLL-WPF and SOGI-PLL under distorted voltage. Figure 11 shows the performance comparison of the SOGI-PLL-WPF and the basic SOGI-PLL under distorted grid voltage. It is clear that the SOGI-PLL-WPF is more robust and efficient than the SOGI-PLL under such abnormalities of the PCC voltage, in which the frequency estimated using SOGI-PLL contains a high level of ripple compared to SOGI-PLL-WPF method in both simulation and experimental results.
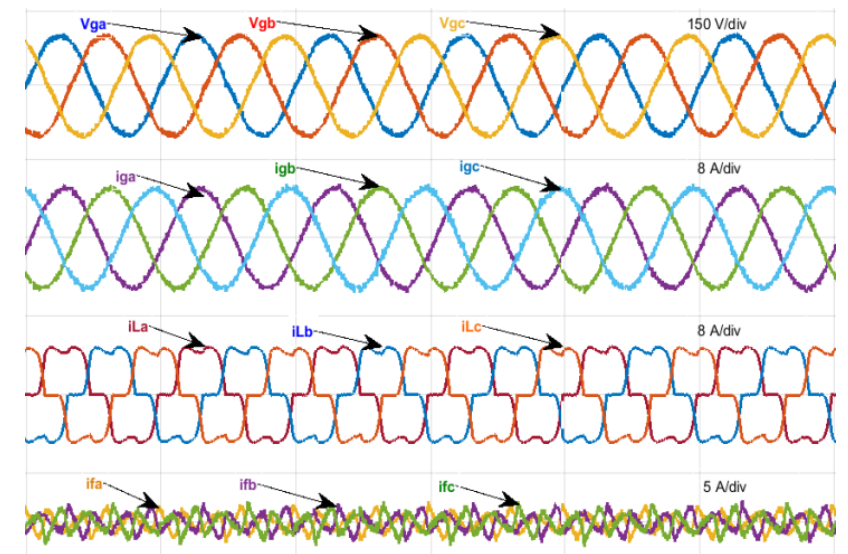

$b$

Fig. 8. Behavior of the SAPF under sinusoidal grid voltage condition: $a$-simulation results, $b$ - experimental results

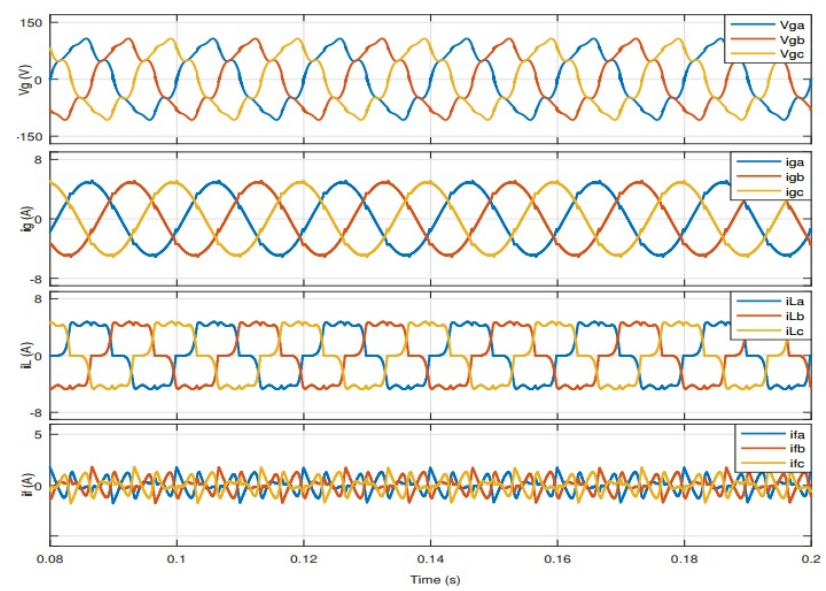

$a$
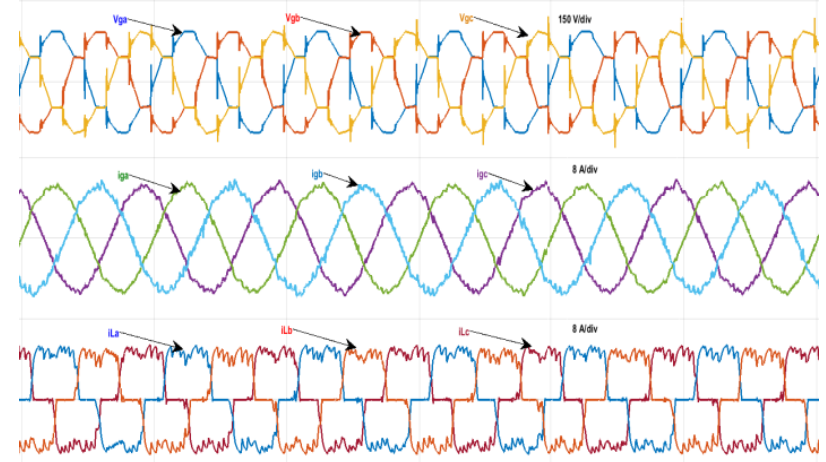

(1)

$b$

Fig. 9. Behavior of the SAPF under distorted grid voltage condition: $a$ - simulation results, $b$ - experimental results 

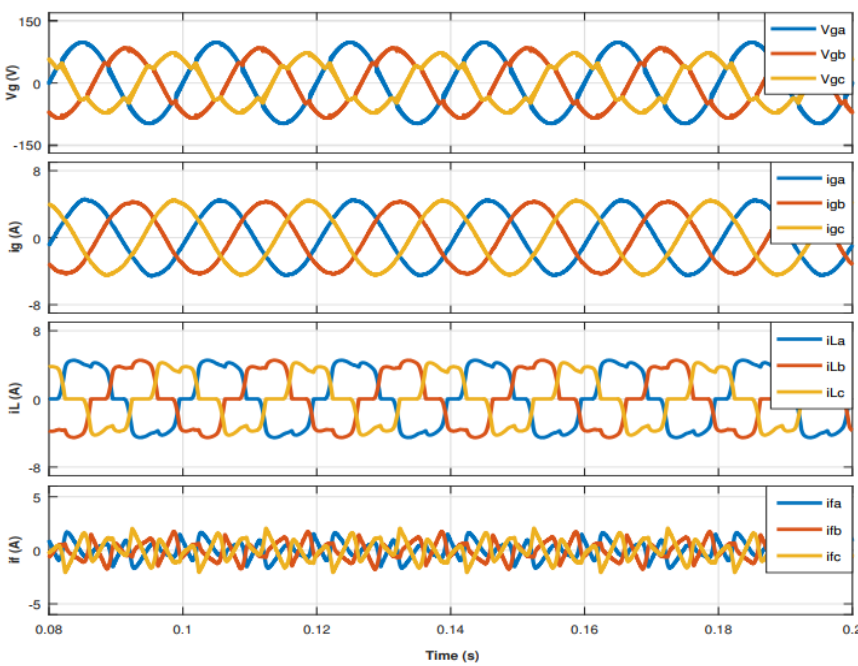

$a$
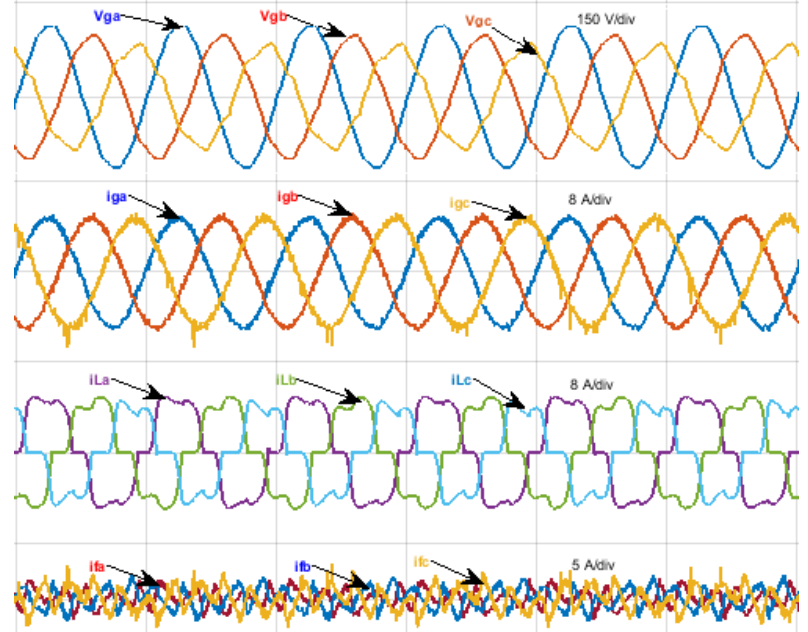

$b$

Fig. 10. Behavior of the SAPF under unbalanced grid voltage condition: $a$-simulation results, $b$ - experimental results
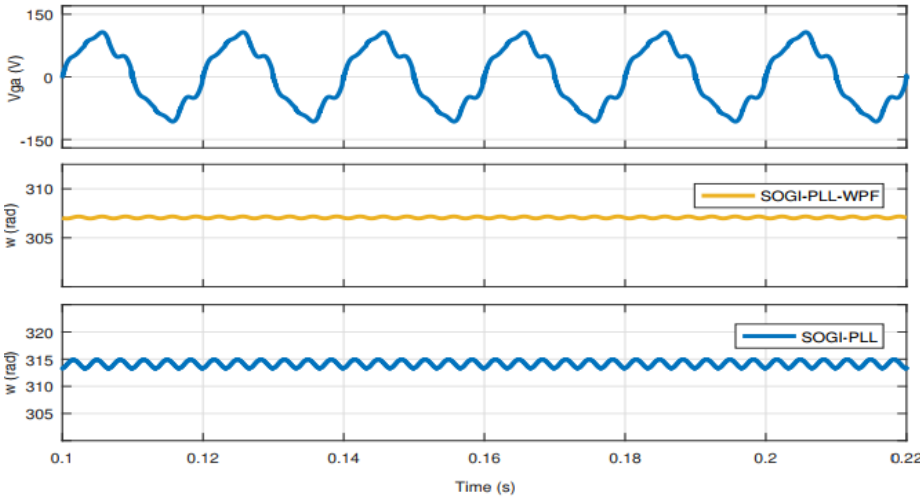

$a$

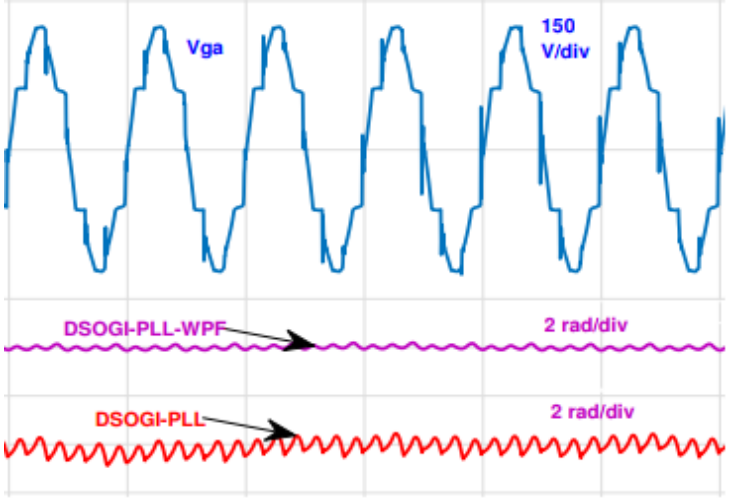

$b$

Fig. 11. Performance of SOGI-PLL-WPF and SOGI-PL: $a$ - simulation results, $b$ - experimental results

Conclusion. This proposed work has extended the straightforward prefiltering method based on double second-order generalized integrator with prefilter to extract the reference harmonic current components for the control of the three-phase shunt active power filter, allowing a significant attenuation of the harmonics of the source currents and consequently improving its quality. The performance of the proposed configuration has been proven, where the total harmonic distortion has had significant reduction from about $22 \%$ to less than $4.2 \%$ under sinusoidal voltage, in distorted voltage, the total harmonic distortion is mitigated to about $4.6 \%$ and nearly to $4.3 \%$ under unbalanced voltage, which demonstrates the effectiveness and robustness of the proposed algorithm. This also signifies that even the abnormalities of the point of common coupling voltage, the phaselocked loop based on double second-order generalized integrator with prefilter has estimated grid fundamental voltage magnitude and frequency accurately and makes the shunt active power filter always synchronized. The main advantage of the represented structure appeared in the results of the experiment, where it has given good results with reduced computation time. The experimental results have been quite identical to those obtained by simulation in MATLAB-Simulink.

\section{REFERENCES}

1. Taskovski D., Koleva L., Milchevski A., Dimcev V. Near perfect reconstruction filter banks for power quality analysis. Metrology and Measurement Systems, 2013, vol. 20, no. 3, pp. 359-370. doi: 10.2478/mms-2013-0031.

2. Tugay D.V. The phase reactor inductance selection technique for power active filter. Electrical Engineering \& Electromechanics, 2016, no. 6, pp. 31-38. doi: 10.20998/2074272X.2016.6.06.

3. Patil K., Patel H.H. Modified SOGI based shunt active power filter to tackle various grid voltage abnormalities. Engineering Science and Technology, an International Journal, 2017, vol. 20, no. 5, pp. 1466-1474. doi: 10.1016/j.jestch.2017.10.004.

4. Naderi Y., Hosseini S.H., Ghassem Zadeh S., MohammadiIvatloo B., Vasquez J.C., Guerrero J.M. An overview of power quality enhancement techniques applied to distributed generation in electrical distribution networks. Renewable and Sustainable Energy Reviews, 2018, vol. 93, pp. 201-214. doi: 10.1016/j.rser.2018.05.013.

5. Garcia Campanhol L.B., Oliveira da Silva S.A., Goedtel A. Application of shunt active power filter for harmonic reduction and reactive power compensation in three-phase four-wire systems. IET Power Electronics, 2014, vol. 7, no. 11, pp. 28252836. doi: 10.1049/iet-pel.2014.0027.

6. Soares V., Verdelho P., Marques G.D. An instantaneous active and reactive current component method for active filters. 
IEEE Transactions on Power Electronics, 2000, vol. 15, no. 4, pp. 660-669. doi: 10.1109/63.849036.

7. Sena K.V. Power Quality Improvement using Five Level Active Power Filter with SRF Control Technique. International Journal of Advanced Research in Electrical, Electronics and Instrumentation Engineering, 2014, vol. 3, no. 7, pp. 1046810476. doi: 10.15662/ijareeie.2014.0307012.

8. Akagi H., Kanazawa Y., Nabae A. Instantaneous reactive power compensators comprising switching devices without energy storage components. IEEE Transactions on Industry Applications, 1984, vol. IA-20, no. 3, pp. 625-630. doi: 10.1109/TIA.1984.4504460.

9. Wang H., Li Q., Wu M. Investigation on a new algorithm for instantaneous reactive and harmonic currents detection applied to intensive nonlinear loads. IEEE Transactions on Power Delivery, 2007, vol. 22, no. 4, pp. 2312-2318. doi: 10.1109/TPWRD.2007.905379.

10. Qasim M., Kanjiya P., Khadkikar V. Artificial-NeuralNetwork-Based Phase-Locking Scheme for Active Power Filters. IEEE Transactions on Industrial Electronics, 2014, vol. 61, no. 8, pp. 3857-3866. doi: 10.1109/TIE.2013.2284132.

11. Bhattacharya A., Chakraborty C. A Shunt Active Power Filter With Enhanced Performance Using ANN-Based Predictive and Adaptive Controllers. IEEE Transactions on Industrial Electronics, 2011, vol. 58, no. 2, pp. 421-428. doi: 10.1109/TIE.2010.2070770.

12. Jarupula S., Mannam V.G.R., Vutlapalli N.R. Power quality improvement in distribution system using ANN based shunt active power filter. International Journal of Power Electronics and Drive Systems (IJPEDS), 2015, vol. 5, no. 4, pp. 568-575. doi: 10.11591/ijpeds.v5.i4.pp568-575.

13. Xiao C., Pei X., Y Liu., Lu Y., Wang C., Xu F. Adaptive harmonic current compensation method with SAPF based on SOGI. 2018 IEEE International Power Electronics and Application Conference and Exposition (PEAC), 2018, pp. 1-6. doi: 10.1109/PEAC.2018.8590342.

14. Matas J., Castilla M., Miret J., García de Vicuña L., Guzman R. An adaptive prefiltering method to improve the speed/accuracy tradeoff of voltage sequence detection methods under adverse grid conditions. IEEE Transactions on Industrial Electronics, 2014, vol. 61, no. 5, pp. 2139-2151. doi: 10.1109/TIE.2013.2274414.

15. Li W., Ruan X., Bao C., Pan D., Wang X. Grid synchronization systems of three-phase grid-connected power converters: a complex-vector-filter perspective. IEEE Transactions on Industrial Electronics, 2014, vol. 61, no. 4, pp. 1855-1870. doi: 10.1109/TIE.2013.2262762.

16. Yada H.K., Murthy M.S.R., Prakash K. A Novel Control Algorithm for DSTATCOM Based on Three-Phase Dual SOSOGI-PLL under Non-Ideal Grid Voltage Conditions Including DC-Offset. International Journal of Applied Engineering Research, 2017, vol. 12, no 10, pp. 2480-2488.

17. Chilipi R., Al Sayari N., Al Hosani K., Fasil M., Beig A.R. Third order sinusoidal integrator (TOSSI)-based control algorithm for shunt active power filter under distorted and unbalanced voltage conditions. International Journal of Electrical Power \& Energy Systems, 2018, vol. 96, pp. 152-162. doi: 10.1016/j.ijepes.2017.09.026.

Received 24.01.2020

Sami Kalkoul ${ }^{1}$, PhD, Associate Professor,

Hocine Benalla ${ }^{1}$, PhD, Professor,

Khalil Nabti ${ }^{1}$, PhD, Professor,

Reama Abdellatif ${ }^{2}$, PhD, Professor,

${ }^{1}$ Mentouri Brothers University, Constantine 1,

Campus Ahmed Hamani Zarzara, Route d'Ain el Bey,

Constantine, 25000, Algeria.

e-mail: sami.kalkoul@lec-umc.org, benalladz@yahoo.fr,

khalilnb2003@gmail.com,

${ }^{2}$ System Engineering Department,

École Supérieure d'Ingénieurs en Électrotechnique et

Électronique (ESIEE),

Cité Descartes, 2 Boulevard Blaise Pascal,

93160 Noisy-le-Grand, France.

e-mail: abdellatif.reama@esiee.fr

How to cite this article:

Kalkoul S., Benalla H., Nabti K., Abdellatif R. An adaptive harmonic compensation strategy for three-phase shunt active power filter based on double second-order generalized integrator with prefilter. Electrical engineering \& electromechanics, 2020, no. 3, pp. 58-64. doi: 10.20998/2074-272X.2020.3.09. 